\title{
Breast Cancer Trend in Iran from 2000 to 2009 and Prediction till 2020 using a Trend Analysis Method
}

\author{
Bibihajar Zahmatkesh ${ }^{1}$, Afsaneh Keramat ${ }^{2}$, Nasrinossadat Alavi ${ }^{3}$, Ahmad \\ Khosravi $^{4}$, Ahmad Kousha ${ }^{5}$, Ali Ghanbari Motlagh ${ }^{6}$, Mahboobeh Darman ${ }^{7}$, \\ Elham Partovipour ${ }^{8}$, Reza Chaman'*
}

\begin{abstract}
Background: Breast cancer is the most common cancer in women worldwide with a rising incidence rate in most countries. Considering the increase in life expectancy and change in lifestyle of Iranian women, this study investigated the age-adjusted trend of breast cancer incidence during 2000-2009 and predicted its incidence to 2020. Materials and Methods: The 1997 and 2006 census results were used for the projection of female population by age through the cohort-component method over the studied years. Data from the Iranian cancer registration system were used to calculate the annual incidence rate of breast cancer. The age-adjusted incidence rate was then calculated using the WHO standard population distribution. The five-year-age-specific incidence rates were also obtained for each year and future incidence was determined using the trend analysis method. Annual percentage change (APC) was calculated through the joinpoint regression method. Results: The bias adjusted incidence rate of breast cancer increased from 16.7 per 100,000 women in 2000 to 33.6 per 100,000 women in 2009. The incidence of breast cancer had a growing trend in almost all age groups above 30 years over the studied years. In this period, the age groups of 45-65 years had the highest incidence. Investigation into the joinpoint curve showed that the curve had a steep slope with an APC of $23.4 \%$ before the first joinpoint, but became milder after this. From 2005 to 2009, the APC was calculated as $2.7 \%$, through which the incidence of breast cancer in 2020 was predicted as 63.0 per 100,000 women. Conclusions: The age-adjusted incidence rate of breast cancer continues to increas in Iranian women. It is predicted that this trend will continue until 2020. Therefore, it seems necessary to prioritize the prevention, control and care for breast cancer in Iran.
\end{abstract}

Keywords: Trend - Iran - breast - cancer - joinpoint analysis

Asian Pac J Cancer Prev, 17 (3), 1493-1498

\section{Introduction}

Breast cancer is the most common cancer among women in the developed and developing countries (Jemal et al., 2011; Benson and Jatoi, 2012; Ferlay et al., 2015) and its incidence is rising due to the increased life expectancy, urbanization, and lifestyle changes(Benson and Jatoi, 2012).

The age-adjusted incidence rates of breast cancer are on the rise in most countries, especially in those such as Japan, China, Eastern and Southeast Europe, which had a low incidence rate before (Parkin et al., 2005). In the U.S., however, the incidence of breast cancer in women did not change during 2002-2011(Kohler et al., 2015).

The incidence of breast cancer has increased over a tenyear period in the East and Southeast Asian countries (Shin et al., 2010). A constant increase has been observed in the incidence of breast cancer in the West Asian countries (Salim et al., 2009). In India, the cancer registration systems have reported an increasing ratio of breast cancer to other types of cancer during 1990-2003 (Takiar and Srivastav, 2008).

The total burden of breast cancer has been doubled during 1975 to 2000 , and it is likely to be doubled again by 2030 , mainly in low and middle income countries where there is a lack of resources and predictive plan for dealing with current and future conditions (Boyle, 2010).

In Iran, cancer is the third leading cause of mortality after cardiovascular diseases and traffic accidents. Every year, over 30,000 Iranians die of cancer. Due to increase in life expectancy and elderly population, the incidence of cancer is expected to be doubled in the next two decades

${ }^{1}$ Pathology Department, School of Nursing and Midwifery, ${ }^{4}$ Pathology Department, Center for Health Related Social and Behavioral Sciences Research, ${ }^{2}$ School of Nursing and Midwifery, Shahroud University of Medical Sciences, Shahroud, ${ }^{3}$ Breast Cancer Research Center, ACECR, ${ }^{6}$ Radiation Oncology, Shahid Beheshti University of Medical Sciences, ${ }^{7}$ Expert At Noncomunicable Disease Center, ${ }^{8} \mathrm{MS}$, Non-Communicable diseases, Deputy of Health, Ministry of Health and Medical Education, Tehran, ${ }^{5}$ Faculty of Health Tabriz University of Medical Sciences,Tabriz, ${ }^{9}$ Department of Community Medicine, School of Medicine, Yasuj University of Medical Sciences, Yasuj, Iran*For correspondence: rezachaman@yahoo.com 
(Center for Disease Control and Prevention, 2010).

Cancer registration system reveals an increasing trend of breast cancer incidence (Taheri et al., 2012; Enayatrad and Salehiniya, 2015), with the Northern and Central provinces at the top (Jafari-Koshki et al., 2014; Enayatrad and Salehiniya, 2015). Breast cancer is the most common cancer among Iranian women(IARC, 2012)

Health officials and policy makers in every country require information on the future burden of cancer to develop prevention programs, prioritize the activities properly, allocate resources, and evaluate cancer control or treatment programs (Jiang et al., 2007). In this study, the age- adjusted- specific incidence of breast cancer was investigated in Iran in a ten-year period (2000 to 2009), and its trend was projected using trend analysis to take an effective step in controlling breast cancer and improving women's health.

\section{Materials and Methods}

The first stage: determination of the age-adjusted incidence of breast cancer in Iran

The data obtained from the cancer registration system in the center for non-communicable diseases control of Iran Ministry of Health and Medical Education were used to investigate the incidence of breast cancer between the years 2000-2009. The first and second reports of Iranian cancer registration system were published in 1986 and 2007 , respectively. It should be noted that before 2007, cancer cases were registered only in the center of disease control, based on the pathological reports; whereas, from 2008 , the population-based cancer registration program was implemented in 20 universities as a supplement for the pathological records. Population-based cancer registration monitors the frequency of new cancer cases (incidence) in the population in each year and collects the records from various sources (medical centers, clinicians and pathologists, and death certificates) (Center for Disease Control and Prevention, 2012).

To determine the annual incidence of breast cancer in the age groups of 0-4, 5-9, 10-14-10, 15-19, 20-24, 25-29, 30-34, 35-39, 40-44, 45-49, 50-54, 55-59, 60-64, 65-69, 70-74, 75-79, 80-84, and $\geq 85$ years, the 1996 and 2006 census results were first used to calculate the women's population in the 5-year age groups through the cohortcomponent method. The incidence of breast cancer in each age group was then determined after eliminating the invalid data from the cancer registration data during years 2000-2009 collected by the Ministry of Health and Medical Education. Then The frequency of breast cancer has been corrected based on the percentage of national cancer registration program covering $29 \%, 60 \%$ and $86.7 \%$, respectively, for the years 2000, 2003 and 2007 (Center for Disease Control and Prevention, 2012) were calculated and standardized.

The second stage: determination of the trend of ageadjusted incidence of breast cancer in Iran and its projection for the next decade

The ten-year trend of breast cancer incidence in Iran was investigated using the trend analysis method. This technique is employed to identify the change pattern or trend in a series of observations. The model aims at examining the increase or decrease in the incidence of cancer over time, as well as the rate of such changes. The cancer incidence trend assessment may be based on the number of diagnosed cases or cancer-related death over a period of time. Due to the effect of demographic changes and changes in risk factors over time, trend analysis is preferred in most cases for calculating the cancer incidence and mortality rates. To account for the changes in the population distribution over time, the incidence and mortality rates are usually adjusted for the population size, and the sex and age structure of it. Accordingly, ageadjusted rates are used to determine the trend in cancer incidence rates (Jiang et al., 2007).

In some types of cancer, changes in exposure to risk factors or the implementation of new screening programs or other interventions may affect the trend or incidence of cancer in the following years. Sudden changes in the population's structure, such as new migration patterns, may change the cancer incidence trend. Therefore, determination of the points where changes are statistically significant through the trend analysis model is of special importance Joinpoint regression was used to determine these points and the trend of the changes (Jiang et al., 2007).

The extrapolation of the trend in cancer incidence from the registration system data was based on two assumptions: $i$ ). The collected data were sufficient for the accurate projection of the trend in cancer incidence. ii). The trend observed in the data would be unchanged over the next ten years (National Cancer Registry Ireland, 2006).

\begin{tabular}{ll}
\hline Details of the models used in the trend analysis \\
\hline Log-linear model & $\ln \mathrm{R}_{\mathrm{it}}=\mathrm{a}_{\mathrm{i}}+\mathrm{b}_{\mathrm{i}} \mathrm{t}$ \\
Linear model & $\mathrm{R}_{\mathrm{it}}=\mathrm{a}_{\mathrm{i}}+\mathrm{b}_{\mathrm{i}} \mathrm{t}$ \\
where & $\mathrm{i}=$ age group \\
$\mathrm{R}=$ age - specific mortality rate & $\mathrm{a}_{\mathrm{i}}=$ underlying base rate \\
$\mathrm{t}=$ period ( year of death ) & $\mathrm{b}_{\mathrm{i}}=$ increment rate for individual age groups \\
$\mathrm{b}=$ increment rate for all age groups
\end{tabular}

There is a consensus that the use of Poisson linear or log-linear models for age-specific incidence rates provides a good proportion of data while yielding accurate predictions. Most studies suggest that Poisson linear or log-linear models provide the best fit for the age-specific cancer incidence rates (National Cancer Registry Ireland, 2006).

The main assumption of this model is that the factors, which affect age-specific incidence rates, e.g. risk factors, and consequently, their overall effect, vary linearly with time in each age group. Therefore, the effect of the relative distribution of these factors on the disease incidence is not required to be known (National Cancer Registry Ireland, 2006). The linear model assumes a constant change in the age groups, whereas the change takes log logarithmic values in the log-linear model (National Cancer Registry Ireland, 2006).

Thus, data such as the annual age-specific incidence rate, desired period, the frequency of breast cancer in each age group by year, based on the available data and also corrected the frequency of breast cancer based cancer 
Breast Cancer Trend in Iran from 2000 to 2009 and Prediction till 2020 with a Trend Analysis Method

registry system cover $29 \%, 60 \%$ and $86.7 \%$, respectively, for the years 2000, 2003 and 2007, the population of each age group by year, and the standard population, extracted from the WHO's standard distribution in 2000 prepared based on the world's average population between 2000 and 2025, were used to calculate the trend with this model.

Practically, both linear and log-linear models often provide good fit for short-term data. When applied to cancer cases, negligible differences have been observed in deviance between the two models, and no more efficient model has been identified in this regard. However, although both models may perform well in data fitting, the projections provided by the models can be quite different (National Cancer Registry Ireland, 2006).

\section{Results}

Based on the available data, the incidence of breast

Table 1. Observed and Modeled Age- adjusted Breast Cancer Rates between 2000-2009

\begin{tabular}{|c|c|c|c|c|}
\hline Year & $\begin{array}{c}\text { Age } \\
\text { adjusted } \\
\text { rate with } \\
\text { reported } \\
\text { cases } \\
\pm \text { Standard } \\
\text { Error }\end{array}$ & $\begin{array}{c}\text { Modeled } \\
\text { cancer } \\
\text { rate }\end{array}$ & $\begin{array}{c}\text { Bias } \\
\text { and Age } \\
\text { adjusted rate } \\
\pm \text { Standard } \\
\text { Error }\end{array}$ & $\begin{array}{c}\text { Bias } \\
\text { adjusted } \\
\text { cancer } \\
\text { rate }\end{array}$ \\
\hline 2000 & $5.49 \pm 0.17$ & 4.71 & $18.91 \pm 0.31$ & 16.65 \\
\hline 2001 & $6.05 \pm 0.17$ & 7.88 & $15.13 \pm 0.27$ & 20.55 \\
\hline 2002 & $13.50 \pm 0.25$ & 13.17 & $27.00 \pm 0.35$ & 25.36 \\
\hline 2003 & $16.96 \pm 0.27$ & 15.87 & $28.27 \pm 0.35$ & 26.88 \\
\hline 2004 & $18.15 \pm 0.28$ & 19.13 & $27.21 \pm 0.34$ & 28.50 \\
\hline 2005 & $23.12 \pm 0.31$ & 23.05 & $31.49 \pm 0.36$ & 30.22 \\
\hline 2006 & $24.13 \pm 031$ & 24.62 & $30.17 \pm 0.35$ & 31.03 \\
\hline 2007 & $27.46 \pm 0.32$ & 26.29 & $31.68 \pm 0.35$ & 31.85 \\
\hline 2008 & $27.80 \pm 0.32$ & 28.08 & $32.06 \pm 0.34$ & 32.70 \\
\hline 2009 & $29.73 \pm 0.32$ & 29.98 & $34.29 \pm 0.35$ & 33.58 \\
\hline
\end{tabular}
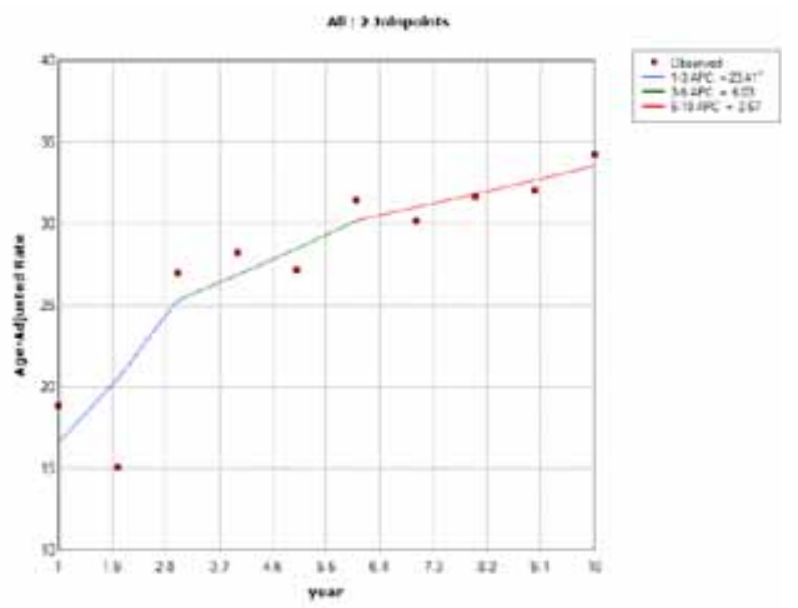

Figure 1. Trend of Age-adjusted Incidence of Breast Cancer Using coverage rate for cancer registration program Frequency During 2000-2009 Obtained by Trend Analysis cancer has had an increasing trend in Iran from 2000 to 2009. However, the pace of this trend has been changing

Table 2. Modeled Annual Percentage Change in Breast Cancer Incidence Rates 2000-2009

\begin{tabular}{|c|c|c|c|}
\hline Cancer & Period & $\begin{array}{c}\text { Annual } \\
\text { Percentage } \\
\text { Change(APC) }\end{array}$ & $\begin{array}{c}95 \% \\
\text { Confidence } \\
\text { Limits }\end{array}$ \\
\hline $\begin{array}{c}\text { Breast } \\
\text { cancer }\end{array}$ & $2000-2002$ & 23.4 & $5.7-44.1$ \\
\hline $\begin{array}{c}\text { Breast } \\
\text { cancer }\end{array}$ & $2003-2005$ & 6 & $-5.4-18.8$ \\
\hline $\begin{array}{c}\text { Breast } \\
\text { cancer }\end{array}$ & $2005-2009$ & 2.7 & $-0.5-5.9$ \\
\hline $\begin{array}{c}\text { Breast } \\
\text { cancer }\end{array}$ & $2000-2009$ & 8.1 & $5.5-10.8$ \\
\hline
\end{tabular}

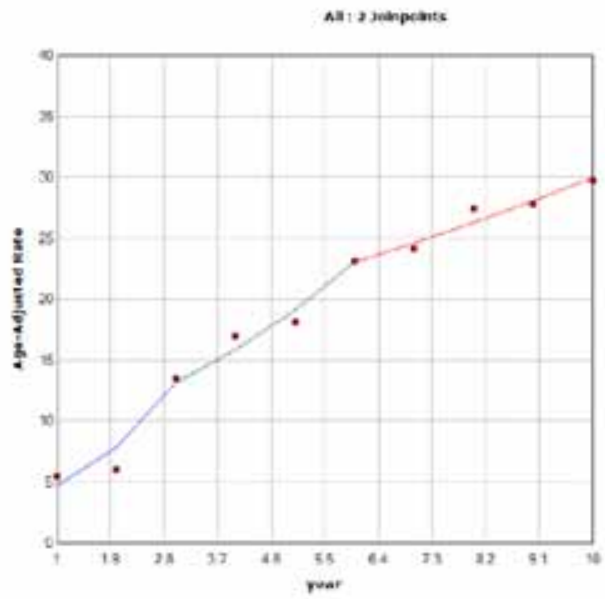

Figure 2. Trend of Age-adjusted Incidence of Breast Cancer Using Available Data During 2000-2009 Obtained by Trend Analysis

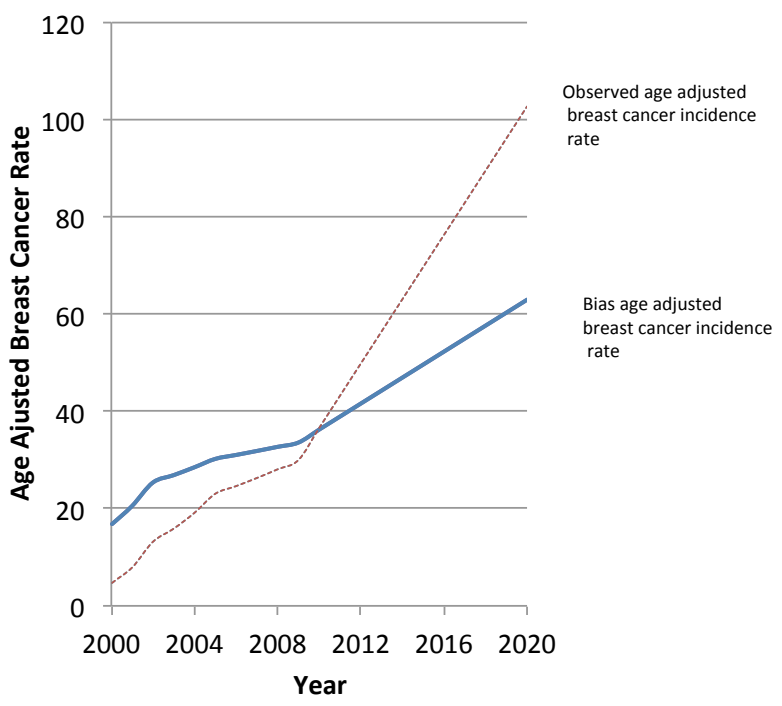

Figure 3. Indicates the Increasing Trend of AgeAdjusted Incidence Rate of Breast Cancer in The Coming Years (by 2020), which was Obtained Through the Linear-Log Model. As a result, the trend is reinforced as the years go by 
Table 3. Age-Specific Incidence Rate of Breast Cancer in Each Age Group During 2000-2009

\begin{tabular}{|l|l|l|l|l|l|l|l|l|l|l|}
\hline Age groups (year) & 2000 & 2001 & 2002 & 2003 & 2004 & 2005 & 2006 & 2007 & 2008 & 2009 \\
\hline $30-34$ & 12.48 & 11.79 & 19.02 & 17.98 & 17.72 & 18.80 & 18.64 & 19.67 & 17.82 & 20.25 \\
\hline $35-39$ & 25.80 & 16.54 & 32.14 & 34.40 & 32.22 & 40.27 & 39.47 & 37.37 & 37.30 & 39.34 \\
\hline $40-44$ & 38.98 & 33.24 & 60.27 & 62.88 & 58.17 & 63.86 & 61.19 & 63.43 & 66.28 & 63.94 \\
\hline $45-49$ & 51.74 & 41.62 & 71.90 & 77.85 & 75.85 & 85.62 & 77.86 & 82.89 & 86.24 & 88.63 \\
\hline $50-54$ & 51.33 & 43.68 & 84.03 & 81.42 & 78.40 & 97.22 & 83.32 & 92.16 & 91.02 & 96.97 \\
\hline $55-59$ & 44.12 & 35.51 & 68.01 & 80.81 & 70.49 & 84.16 & 88.37 & 91.82 & 87.57 & 99.63 \\
\hline $60-64$ & 51.62 & 35.00 & 62.35 & 63.24 & 68.76 & 85.84 & 85.34 & 86.24 & 93.43 & 107.78 \\
\hline $65-69$ & 41.17 & 35.04 & 57.48 & 65.38 & 63.61 & 69.70 & 74.75 & 72.52 & 77.64 & 85.90 \\
\hline $70-74$ & 36.68 & 35.08 & 53.50 & 53.41 & 56.99 & 61.24 & 68.52 & 64.76 & 64.69 & 76.84 \\
\hline $75-79$ & 54.89 & 39.50 & 48.91 & 52.69 & 57.72 & 61.41 & 59.07 & 63.11 & 55.69 & 65.64 \\
\hline $80-84$ & 25.00 & 24.46 & 48.43 & 48.41 & 56.09 & 47.30 & 43.24 & 56.73 & 54.09 & 57.96 \\
\hline $85 \leq$ & 27.12 & 13.94 & 53.13 & 38.45 & 27.79 & 32.42 & 38.90 & 46.70 & 62.90 & 44.32 \\
\hline
\end{tabular}

in that age-adjusted incidence increased from 4.71 in 2000 to 13.17 in 2002 and then to 29.98 [per 100,000] in 2009. Crude and age-adjusted incidence rates of breast cancer during this time period by each year is shown in Table 1.

Using the coverage rate for cancer registration program in the years 2000, 2003 and 2007, the frequency of breast cancer was corrected for each year, respectively. With this method, the age-standardized incidence rate of 16.65 in 2000 to 26.88 in 2003 and 33.58 in 2009 (Table 1).

Results in Table 2 show a steep rise in the incidence of breast cancer in Iranian women from 2000 to 2002 (23.40\% APC). This trend decreased by $2.7 \%$ annually during 2005-2009 (Table 2).

Breast cancer incidence in each of the age groups (30-34, 35-40, 39-44, ... and over 85) also continued a growing trend with fluctuation in some groups (Table 3 ).

An increasing trend of breast cancer incidence was observed in almost all age groups during the studied years (2000-2009). Interestingly, in 2009 compared to 2008, a declining trend was observed in the trend of breast cancer incidence in the 40-44 and over 85 years age group (Table 3 ).

Two point becomes clear by investigating the annual changes $(\%)$ in the age-adjusted incidence rates of breast cancer in Iran (Table 2) during 2000 to 2009. The growing trend in the breast cancer incidence with a steep slope during 2000 to 2002 can be attributed to due to the evolution of Iranian cancer registration system, which leads to the identification of higher number of patients. Therefore, the annual change (\%) during 2005 to 2009, which had a mild slope (Figure 1), was used to predict the age-adjusted incidence rate of breast cancer during 2010-2020.

\section{Discussion}

Results showed that, bias-age-adjusted incidence of breast cancer follows an increasing trend (from 16.65 in 2000 to 33.58 in 2009, per 100,000 women). Similar trend was observed in almost all age groups. Previous studies also have shown an increasing ASR trend in breast cancer incidence (Yang et al., 2004; Ozmen, 2008; Shin et al., 2008; Takiar and Srivastav, 2008; Mousavi SM et al., 2009; Shin et al., 2010; Beiki et al., 2012; Taheri et al., 2012; Asadzadeh Vostakolaei et al., 2013; Fateh and Emamian, 2013; Kiadaliri, 2013; Enayatrad and Salehiniya, 2015).

In our study, the slope in the age-adjusted incidence of breast cancer was steeper between 2000 and 2002 (16.65 to 25.36 per 100,000 women); however, an almost constant and mild slope was observed in the following years (26.88 in 2003 to 33.58 per 100,000 women in 2009) (Figure 1). According to the state report of the registered cancer cases, $29 \%$ of the expected cancer cases were recorded in Iran in 2000. Upon improving the registration process in $2003,60 \%$ of the expected cancer cases were reported in 2003, and 86.7\% in 2007(Center for Disease Control and Prevention, 2012). Improved cancer registration in Iran resulted in better identification of patients in 2002. This can justify a large part of the observed rise as well as the steep slope of the ASR trend between 2000 and 2002.

Studies in the U.S.(American cancer society, 2013; American Cancer Society, 2015), as well as the study by Daubisse-Marlic in France, have shown a declining trend in the annual incidence of breast cancer from 2003 onwards, which can be due to decreasing the administration of hormone replacement therapy (HRT) (Chlebowski et al., 2009; Daubisse-Marliac et al., 2011; American Cancer Society, 2015). This is inconsistent with our results and growing trend in the incidence of breast cancer in Iran.

In our study, the age group of 75-79 years had the highest incidence in 2000 , followed by the age groups of 45-49, 60-64, and 50-54 years. In 2001, the highest incidence was observed in the age groups of 50-54 and 45-49 years. In 2002-2005 and 2007-2008, the highest incidence was observed in the age group of 50-54 years, while during 2006 the highest incidence was observed in the age group of 55-59 years in 2009, the highest incidence was observed in the age group of 60-64 years and the incidence rate declined after this age group.

The highest age-specific incidence during 2005 was observed in the age group of 50-59 years, which is consistent with the results reported by Husseini et al. 
(Hosseini et al., 2013). In 2000, the age group 49-45 years had the highest incidence and in 2001-2005 this age group was rank second and fourth in the years 20062009. Other studies have reported the highest incidence of breast cancer in the age group of 45-49 years (Yip et al., 2006; Lee et al., 2007; Mousavi SM et al., 2009; Jung et al., 2013). In Iraq, during 2000-2009, the highest incidence was observed in the age group of 50-59 and 60-69 yeas (98.0 and 82.7, respectively). The incidence was then reduced to 44.9 in the age group of 70 years and higher (AL-Hashimi and Wang, 2014), which is somewhat consistent with our results.

An increasing trend of breast cancer incidence was observed in almost all age groups during the studied years (2000-2009). The incidence in 2000 increased with aging until 50 years, and almost constant to 70 years and then reduced, which is partly consistent with the results reported by Asadzadeh in 2013 (Asadzadeh Vostakolaei et al., 2013). In our study, the incidence in 2001-2005 and 2007 increased until to 55 years, in 2006 the growing trend in incidence of this problem continued until the age of 60 years and then reduced. In 2008-2009, the increasing trend in this rate continued until the age of 65 years and then reduced, which is inconsistent with the results reported by Asadzade (Asadzadeh Vostakolaei et al., 2013) who reported a constant trend in breast cancer incidence between the ages of 50 and 70 years followed by a subsequent decline in older age groups. Asadzadeh et al., in 2000 to 2006, used the cancer registration data from 2003 to 2006, as well as the incidence studies in five provinces; whereas, we studied the cancer registration data of the 2000-2009 period. Given the improvements in the cancer registration system, especially in recent years, our study seems to have better covered the registered breast cancer patients.

In a study conducted in Isfahan, Tazhibi reported a growing trend in breast cancer incidence during 20012010 within the age groups of 40-44, 45-49, and 55-59 years, which approximately is consistent with the results of our study (Tazhibi et al., 2014). There are differences between the results of the two studies. In 2009, the incidence rate reduced in the age group of 40-44 years and significantly decreased in the age group of 85 years and higher, which can be attributed to either the focus on only Isfahan or the undercounting the cases in these age groups in the studies of Tazhibi and ours, respectively.

In Tazhibi's study, the maximum annual percentage change in the incidence of breast cancer (6.2\%) during 2001-2010 was observed in the 40-44 years age group (from 17.6 to 25 per 100,000 women during the study) (Tazhibi et al., 2014). In our study, the incidence of breast cancer in the 40-44 years age group was increased from 38.98 to 63.94 per 100,000 ; however, the highest increase was observed in the age group of 60-64 years (from 51.62 to 107.78 per 100,000$)$. The difference in the regional incidence and the scope of study may be the cause of diverse results.

In our study, half the patients with breast cancer in 2009 were younger than 50 , which are partly consistent with the results of other studies (Yip et al., 2006; Bhurgri et al., 2007; Salim et al., 2009).
In our study, the annual percentage change (APC) in the breast cancer incidence during 2000-2002 and 2003-2005 and 2005-2009 was 23.4\%, 6\% and 2.7\%, respectively. The rate of $2.7 \%$ APC seems reasonable considering the improvements in the cancer registration system. The APC in breast cancer incidence during 20002009 was $8.1 \%$ and is somewhat consistent with the results reported by Jung in Korea (APC=7.2\% during 1999-2005) (Jung et al., 2009). In Qom, the APC between 2004-2008 $(13.8 \%)$ was higher than that obtained in our study could be due to limited population and differences in exposure of women with risk factors in the region (Rafiemanesh et al., 2015). In East and South-East Asia, the annual increase in breast cancer ranged from $0.9 \%$ in Philippines to $7.8 \%$ in Korea in women aged 20 years and older (Shin et al., 2010). The differences between the results may be due to the difference in the duration of studies, ethnicities, and the exposure to risk factors.

Iranian women's life expectancy has increased from 44.6 years in 1960 to 73 years in 2014 (Mofrad et al., 2010). In addition, the incidence of cancer in women 55 and older is high. Half the patients in our study were older than 50 years in 2009. Therefore, the incidence is expected to increase due to the higher incidence of cancer in older ages, more and earlier diagnosis driven by the promotion of women's awareness and advances in diagnostic techniques.

An increased incidence of breast cancer has been observed in a ten-year period in the Southeast and Eastern Asian countries. Average annual percentage change in the incidence of breast cancer was $9.7 \%$ in Korea (with low incidence of $9.31 \%$ ), $6.1 \%$ in Taiwan (with the average incidence of $52.5 \%$ ), and $4.4 \%$ in Singapore (with high incidence of $82.2 \%$ ). In Korea, the incidence increased significantly over 1993-2002 in all age groups, except over 70 years. Filipinos had the lowest APC in all age groups. Women aged 50-69 years had significantly higher APC in most countries, except Japan, rural areas of China, and the Philippines (Shin et al., 2010).

In the trend analysis curve (Figure 1), two point stands out in the change trend, before first point, the trend has a steep slope, whereas after that, the slope becomes milder. Therefore, the APC of breast cancer incidence during 2005-2009 was used to predict the age-adjusted incidence rate between 2010 and 2020. Thus, ASR for breast cancer in 2020 was calculated as 62.95 per 100,000 women provided that the prevalence of risk factors and annual mortality and incidence rates would continue with the same trend. This rate is lower than that reported by Asadzadeh( approximately 65 per 100000 ) which could be due to differences in the projection methods.

The incidence of breast cancer is increasing in the Asia Pacific (Yang et al., 2004). A dramatically-increasing trend has been observed in most regions. The possible reasons include decrease in age of menarche, increase in age of menopause, reduced number of pregnancies, increased gestational age, increased height and weight, and the diet changes (Yang et al., 2004).

Incomplete coverage of cancer registration in the period under study, especially during 2000-2003, was one of the limitations of the present study. 
In conclusion, an increasing trend of breast cancer is evident in Iran. In addition, increased number of risk factors along with the demographic changes aggravates the future incidence of breast cancer. Examination of mechanisms to improve the cancer registration systems, accurate assessment of risk factors for breast cancer, development of prevention program, and control of preventable risk factors seem necessary in this regard.

\section{Acknowledgements}

This article is a part of the $\mathrm{PhD}$ thesis ( code: 9340) supported by grant from Shahroud University of Medical Sciences Research Council. We would like to thank the vice-chancellor of education, as well as the vice-chancellor of research and technology of the University for their financial support to carry out the study.

\section{References}

AL-Hashimi MMY, Wang XJ (2014). Breast cancer in Iraq, incidence trends from 2000-2009. Asian Pac J Cancer Prev, 15, 281-6.

American cancer society (2013). Breast cancer facts and figures 2013-2014 [Online]. Atlanta: American Cancer Society.

American Cancer Society (2015). Cancer Facts and Figures 2015 [Online].

Asadzadeh Vostakolaei F, Broeders MJM, Mousavi SM, et al (2013). The effect of demographic and lifestyle changes on the burden of breast cancer in Iranian women: A projection to 2030. Breast, 22, 277-81.

Beiki O, Hall P, Ekbom A, et al (2012). Breast cancer incidence and case fatality among 4.7 million women in relation to social and ethnic background: a population-based cohort study. Breast Cancer Res, 14, 5 .

Benson JR, Jatoi I (2012). The global breast cancer burden. Future Oncol, 8, 697-702.

Bhurgri Y, Kayani N, Faridi N, et al (2007). Patho-epidemiology of Breast Cancer in Karachi 1995-1997'. Asian Pac J Cancer Prev, 8, 215-20.

Boyle P, A. H (2010). The globalisation of breast cancer. Breast Cancer Res Crops, $\mathbf{1 2}, 7$.

Center for Disease Control and Prevention NDCO (2010). Country reports cancer registration 2008. Iran. 8-17.

Center for Disease Control and Prevention NDCO (2012). Country reports cancer registration 2009. Iran. 12-3.

Chlebowski RT, Kuller LH, Prentice RL, et al (2009). Breast cancer after use of estrogen plus progestin in postmenopausal women. New England J Med, 360, 573-87.

Daubisse-Marliac L, Delafosse P, Boitard JB, et al (2011). Breast cancer incidence and time trend in France from 1990 to 2007: a population-based study from two French cancer registries. Ann Oncol, 22, 329-34.

Enayatrad M, Salehiniya H (2015). An investigation of changing patterns in breast cancer incidence trends among Iranian women. Quarterly J Sabzevar Uni Med Sci, 22, 27-35.

Fateh M, Emamian MH (2013). Cancer incidence and trend analysis in Shahroud, Iran, 2000 - 2010. Iran J Cancer Prev, 6, 85-94.

Ferlay J, Soerjomataram I, Dikshit R, et al (2015). Cancer incidence and mortality worldwide: sources, methods and major patterns in GLOBOCAN 2012. Int J Cancer, 136, 359-86.

Hosseini MS, Arab M, Honar BN, et al (2013). Age - specific incidence rate change at breast cancer and its different histopathologic subtypes in Iran and Western countries. Pak
J Med Sci, 29, 1354-7.

IARC. 2012. GLOBOCAN 2012: Estimated age-standardised incidence and mortality rates. Fact Sheets. Population Fact Sheets: women [Online].

Jafari-Koshki T, Schmid VJ, Mahaki B (2014). Trends of breast cancer incidence in Iran During 2004-2008: A Bayesian space-time model. Asian Pac J Cancer Prev, 15, 1557-61.

Jemal A, Bray F, Center MM, et al (2011). Global cancer statistics. CA Cancer J Clin, 61, 69-90.

Jiang Z, Qiu Z, Hatcher J (2007). Joinpoint trend analysis of cancer incidence and mortality using alberta data. 4-9.

Jung KW, Won YJ, Kong HJ, et al (2013). Cancer statistics in Korea: incidence, mortality, survival and prevalence in 2010. Cancer Res Treat, 45, 1-14.

Jung KW, Won YJ, Park S, et al (2009). Cancer statistics in Korea: incidence, mortality and survival in 2005. J Korean Med Sci, 24, 995-1003.

Kiadaliri AA (2013). Social disparity in breast and ovarian cancer incidence in iran, 2003-2009: a time trend province-level study. J Breast Cancer, 16, 372-7.

Kohler BA, Sherman RL, Howlader N, et al (2015). Annual report to the nation on the status of cancer, 1975-2011, featuring incidence of breast cancer subtypes by race/ethnicity, poverty, and State. J Natl Cancer Inst, 107, 1-25.

Lee JH, Yim SH, Won YJ, et al (2007). Population-based breast cancer statistics in Korea during 1993-2002: incidence, mortality, and survival. J Korean Med Sci, 22, 11-6.

Mofrad MH, Shandiz FH, Roodsare FV, et al (2010). Evaluation of ovarian cysts in breast cancer cases on tamoxifen. Asian Pac J Cancer Prev, 11, 161-4.

Mousavi SM, Zheng T, Dastgiri S, et al (2009). Age distribution of breast cancer in the Middle East, implications for screening. Breast J, 15, 677-9.

National Cancer Registry Ireland (2006). Trends in Irish cancer incidence 1994-2002 with predictions to 2020. 5-7.

Ozmen V (2008). Breast cancer in the world and Turkey. Meme Sagligi Dergisi/J Breast Health, 2-5.

Parkin DM, Bray F, Ferlay J, et al (2005). Global cancer statistics, 2002. CA Cancer J Clin, 55, 74-108.

Rafiemanesh H, Rajaei-Behbahani N, Khani Y, et al (2015). Incidence Trend and Epidemiology of Common Cancers in the Center of Iran. Glob J Health Sci, 8, 146-55.

Salim EI, Moore MA, Al-Lawati JA, et al (2009). Cancer epidemiology and control in the arab world-past, present and future. Asian Pac J Cancer Prev, 10, 3-16.

Shin H-R, Joubert C, Boniol M, et al (2010). Recent trends and patterns in breast cancer incidence among Eastern and Southeastern Asian women. Cancer Causes and Control, 21, 1777-85.

Shin M, Oh H, Ahn Y (2008). Ten year trend of cancer incidence in Seoul, Korea: 1993-2002. J Prev Med Public Health, 41, 92-9.

Taheri NS, Bakhshandehnosrat S, Tabiei MN, et al (2012). Epidemiological pattern of breast cancer in Iranian women: is there an ethnic disparity? Asian Pac J Cancer Prev, 13, 4517-20.

Takiar R, Srivastav A (2008). Time trend in breast and cervix cancer of women in India - (1990-2003). Asian Pac J Cancer Prev, 9, 777-80.

Tazhibi M, Fazeli Z, Babazadeh S (2014). Trends in breast cancer incidence rates by age and tumor characteristics of women in the city of Isfahan for the period 2001-2010: an application of joinpoint analysis. J Res Med Sci, 19, 319- 25.

Yang BH, Parkin DM, Cai L, et al (2004). Cancer burden and trends in the Asian Pacific Rim region. Ann Epidemiol, 14, 596.

Yip CH, Taib N, Mohamed I (2006). Epidemiology of breast cancer in Malaysia. Asian Pac J Cancer Prev, 7, 369-74. 